\title{
Columbus Eye: Interactive Earth Observation from the ISS in Class Rooms
}

\author{
Andreas Rienow, Henryk Hodam, Fabian Selg and Gunter Menz \\ University of Bonn, Germany·a.rienow@geographie.uni-bonn.de
}

Short paper

\begin{abstract}
From May to November 2014, the Astronaut Alexander Gerst fascinated the German public with his live-impressions from the ISS. During his mission "Blue Dot", he used twitter and social media to share his view on our planet with the interested public. Earth observation suddenly became a recurrent topic in the news when Gerst presented cities at night, the aurora borealis, or Gaza at war. At the same time, NASA attached four commercial off-theshelf (COTS) cameras to the European Columbus laboratory of the International Space Station (ISS) observing the Earth in high definition quality. Once installed, the main purposes of NASA's high definition earth viewing (HDEV) mission experiment started, i.e. testing the suitability of COTS HD cameras for upcoming space missions to Moon and Mars. The German educational project "Columbus Eye - Live-Imagery of the ISS in Schools" funded by the German Aerospace Center (DLR) is the exclusive European partner of the HDEV experiment. Accomplished by the University of Bonn, the project is in charge of filing and publishing the HDEV data in a web portal, and, thus, making the data accessible to the public. However, the main goal of Columbus Eye is the didactical valorisetion of the HDEV data for a sustainable use in secondary school lessons. Hence, earth observation from the ISS carries on, even after Gerst returned to Earth. The fascinating views from above provide the basis for mediating knowledge about space travels and remote sensing linked to the Geographical curriculum. The short paper aims to present a) the didactical concept of Columbus Eye, b) the implementation of a learning portal about HDEV, and c) first experiences obtained during a nationwide road show in schools.
\end{abstract}

\section{Columbus Eye - HDEV in Schools}

In our modern information society, remote sensing is a key technology in the aerospace industry and bears increasing economic relevance. New sensors are developed constantly (recent examples are Sentinel-2 \& EnMAP), and the demand for skilled labour is growing steadily. Furthermore, remote sensing influences our everyday life exceedingly - ranging from weather forecasts to reports on climate change or natural disasters. For example, Google Earth cracked the benchmark of 1 billion downloads in 2011. However, the knowledge about remote sensing techniques and products is not widespread. A study by KoLLAR (2012) revealed that a majority of German pupils does not even know that Google Earth is based on satellite images. Although teachers are interested in implementing the topic of earth observation in their classes, the encouragement fails because of confusing, difficult, or

GI_Forum - Journal for Geographic Information Science, 1-2015.

(C) Herbert Wichmann Verlag, VDE VERLAG GMBH, Berlin/Offenbach. ISBN 978-3-87907-558-4.

(C) ÖAW Verlag, Wien. ISSN 2308-1708, doi:10.1553/giscience2015s349. 
ineffective didactical preparation of information (VOß et al. 2008). Here, the HDEV mission provides an opportunity to combine both: the fascination of space travels with the fascination of observing our Earth from above. In order to avoid an 'art for art's sake', a comprehensive portal on HDEV with a special focus on schools has been developed: www. columbuseye.uni-bonn.de. The starting page contains a live stream of HDEV provided by NASA and an ISS tracker. Thus, pupils are "flying with the ISS" and see what astronauts might see in real time. The portal also provides highlights from the HDEV experiment, for example spectacular views from the Mediterranean Sea, the Himalaya, Australia, and sunrises. These views and highlights are not only fascinating, but also informing, and, above all, enable pupils to interact with the HDEV footage. These stages are conducted in the socalled 'observatory' of the portal. It is a special section for teachers and pupils containing interactive learning tools. These tools are based on a technical and didactical paradigm developed in the project 'Remote Sensing in School Lessons' (FIS) since 2007. In the course of school education, imparting media literacy to pupils is regarded as a main educational task. Within this field, the successful and effective handling of 'new media' is of paramount importance (MANDL \& KOPP 2007). Hence, similar to the FIS learning modules (VOß et al. 2011), the pedagogical background of the Columbus Eye observatory is linked to Problem Based Learning theories and skills-oriented teaching. Specific remote sensing techniques are extracted from digital image processing software and reprogrammed in Flash Action Script. The tools are compatible with Windows as well as other OS via the Flash plug-in and can be started online without installing. Products of the HDEV-nadir view form the data background for all tools. HDEV nadir products have a spatial resolution of $500 \mathrm{~m}$; thus they are comparable to space-borne remote sensing sensors with moderate resolution in the visible range of light. A single image is derived by merging a 5-minute HDEV video sequence. The image is connected to information about the pattern, processes and phenomena of the coupled human-environment system.

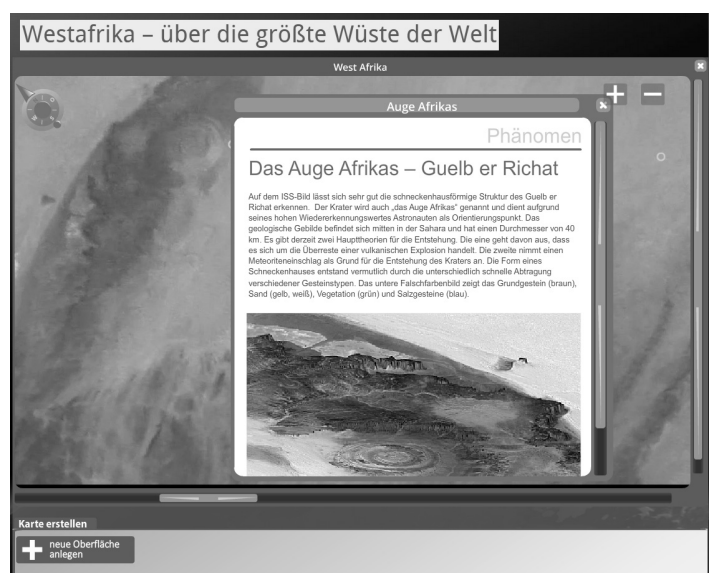

Fig. 1:

The interactive HDEV learning tool 'West Africa - Looking at the world's greatest desert's with exemplary information about the 'Eye of the Sahara'

According to the principles of moderate constructivism (KARAGIORGI \& SYMEOU 2005, NUNES \& MCPHERSON 2003), the learning process requires a high degree of self-organisation and responsibility. This is put forward by the usage of tools within the learning portal. The students are free to construct their own hypotheses based on a spatial analysis, and the 
multi-media preparation of the learning material supports their cognitive learning processes. The integrated spatial analysis is a do-it-yourself classification. In order to handle the manifold information of remote sensing data, a land-cover classification can transform the complexity of spatial imagery into a simple land-cover map showing the most important patterns at a glance. The observatory tools contain a simple function comparable to a supervised minimum-distance classification. The pupils are able to mark relevant training areas incorporating a distinctive spectral mixture (RICHARDS 1999). Afterwards, other areas sharing the spectral similarities of the training areas are automatically selected and depicted in one class. The user can repeat the steps until the image is transformed into a land-cover map. From the evidence of their own eyes, and by virtue of their own analyses, the pupils can see how deceptive images from space can appear, and how complex their evaluation can be. At the same time, working with those images from the ISS orbit demonstrates how powerful remote sensing techniques are, and how massively human interference affects our environment.
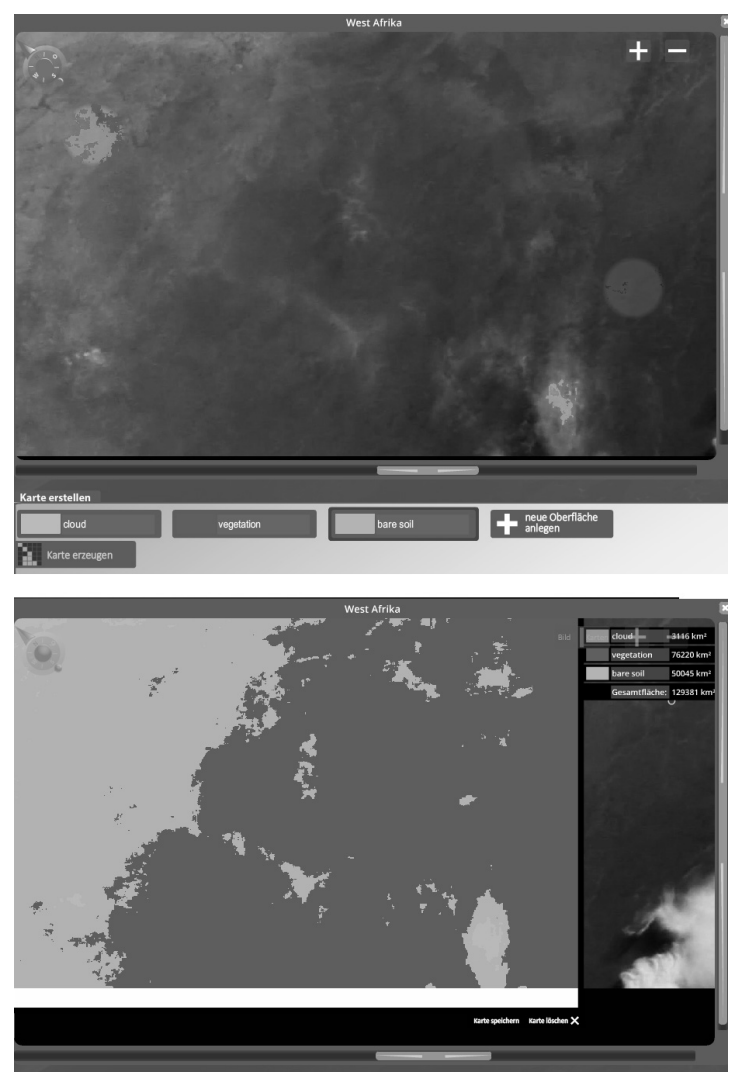

Fig. 2:

The classification process within the observatory tools. Pupils define their land-cover classes and the specific training areas (above). Afterwards, they are only one click away from their own land-cover map (below).

Figure 2 shows an interactive learning tool in the Columbus Eye observatory. An ISS flight over North Africa from the Sahara to the Savanna has been transformed into one large panorama shot. The figure demonstrates the result of classifying the region of interest. The learners can compare their land-cover map with the original image, and reflect on their 
results with the help of information about the area extent. The experiences with the application of the Columbus Eye tools in classes showed that, at first sight, they took the result for granted. Instead of questioning the fact that e.g. clouds may be classified as bare soils erroneously, they needed the area extent and the swipe function to critically assess their results. The tool itself is suitable to foster competences in the field of spatial orienttation and maps, as implicated in the national education standards (DGfG 2014). The pupil's perception of space is trained and they are able to create maps on their own. While the Columbus Eye portal forms the backbone of the project, another important pillar is the ongoing road show in German Schools. It brings the HDEV footage and the mission of Alexander Gerst into the classrooms. Three kinds of Road Show events can be differentiated: lecture hall presentations, classroom visits, and teacher education events. One special event included an exclusive radio call to Alexander Gerst on the ISS. While the pupils were asking their questions dealing with living and working in space, Columbus Eye streamed HDEV live videos, so that the call from the ground was instantly accompanied by imagery from above. However, the main target group are pupils aged 14-18 in Geography classes. The school visits are performed by two researchers of the project and take about two hours. In the beginning, an interactive, multi-media presentation introduces the ISS and Alexander Gerst's expedition. In short movies, Gerst himself explains experiments dealing with microgravity in a child-oriented way. His mission 'Blue Dot' and his view on Earth establish the link between the topic of earth observation and the HDEV experiment. Afterwards, the pupils are asked to apply the Columbus Eye learning tools and answer some questions related to the Earth's surface, e.g. to calculate the snow mass of the Andes. So far, more than 1,000 pupils and 70 teachers were approached directly. The lessons based on HDEV have also been aired on TV and radio, so that a wide, interested public was addressed (ÜBELSTÄDT 2014, ZEITLER 2014). Again, the visits of the Columbus Eye portal and its observatory are reaching a number of 11,000 . The first feedbacks are promising and have already initiated ideas for future developments of the project:

„,... I think, I have gained some new impulses for my teaching. The programs you have developed can be integrated easily into teaching and encourage pupils to deal with the topics at home." (Elke K., teacher)

„My pupils have talked excitedly about the landing today. You have made a big impression on my protégés!"” (Svenja R., teacher)

\section{Conclusions}

If the actions and goals of Columbus Eye are condensed, two catchwords emerge: extensive dissemination and selective intensification. The ISS-HDEV footage is integrated into the Columbus Eye learning portal (www.columbuseye.uni-bonn.de) containing a live stream of the ISS, a web GIS where the HDEV footage is archived and openly accessible, and an observatory comprising the interactive learning material on HDEV. Again, a road show carries HDEV and the ISS-expedition of Alexander Gerst into schools. The ISS live footage as well as the backgrounds of earth observation and space travels are taught to pupils directly. The advanced education of their teachers may also be a way to multiply the recipients and spread the knowledge of remote sensing from space in a sustainable fashion. The pupils experience a new and unfamiliar dynamical astronaut's-eye view, and the value of earth 
observation and space technologies to monitor ongoing processes of the coupled humanenvironment system directing the Earth's future. During the upcoming phases of the project, intuitive user guides as well as didactical commentaries will be developed and published online. Additionally, teaching the teachers how to work with the Columbus Eye observatory will be extended in cooperation with several DLR School Labs. Thus, the implementation of earth observation in schools is facilitated and pushed beyond the application as a mere illustrative teaching element in geography lessons.

\section{References}

DGfG - Deutsche Gesellschaft für Gepgraphie (Ed.) $(2014)^{8}$, Bildungsstandards im Fach Geographie für den Mittleren Schulabschluss mit Aufgabenbeispielen. Bonn.

KARAgiorgi, Y. \& SyMeOU, L. (2005), Translating Constructivism into Instructional Design: Potential and Limitations. Educational Technology \& Society, 8 (1), 17-27.

Kollar, I., (2012), Die Satellitenbild-Lesekompetenz. Empirische Überprüfung eines theoriegeleiteten Kompetenzstrukturmodells für das ,Lesen' von Satellitenbildern. Dissertation PH Heidelberg. opus.ph- heidelberg.de/files/36/Dissertation_Isabelle_Kollar.pdf (04-14-2015).

MANDL, H. \& KopP, B. (2007), Blended Learning: Forschungsfragen und Perspektiven. München.

Nunes, M. B. \& MCPherson, M. (2003), Constructivism vs. objectivism: where is difference for designers of e-learning environments? In: Proc. of the 3rd IEEE International Conference on Advanced Learning Technologies 2003, 496-500.

Richards, A., (1999), Remote Sensing Digital Image Analysis, Berlin.

Voß, K. Goetzke, R. \& HodAm, H. (2008), Wie wird das Thema ,Fernerkundung' im Unterricht angenommen? - Erste Ergebnisse einer Fallstudie. In: JEKEL, T., KOLLER, A. \& Strobl (Eds.), Lernen mit Geoinformationen III. Wichmann, Heidelberg, 8-14.

Voß, K., Goetzke, R., Hodam, H. \& Rienow, A. (2011), Remote Sensing, New Media and Scientific Literacy - A New Integrated Learning Portal for Schools Using Satellite Images. In: JEKEL, T. el al. (Eds.), Learning with GI 2011 - Implementing Digital Earth in Education. Wichmann, Berlin/Offenbach.

ÜBELSTÄDT, S. (2014), Den Planeten im Blick. Schüler schlüpfen in die Rolle von Wissenschaftlern. 3 Sat Nano, TV-Sendung vom 10.11.2014.

ZeITler, A. (2014), Service Bildung - Erdkunde mal anders. Bilder aus dem All fürs Klassenzimmer. WDR 5, Hörfunksendung vom 15.05.2014. http://www.wdr5.de/sendungen/leonardo/service/servicebildung/projektcolumbuseye 10 0.html (04-14-2015). 